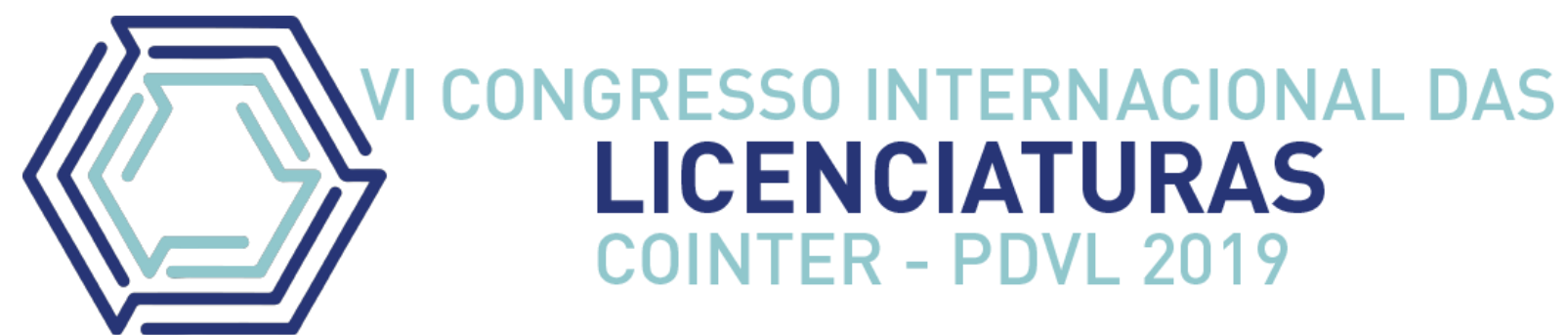

\title{
CIÊNCIA FORENSE: UMA ABORDAGEM DA IDENTIFICAÇÃO HUMANA NO ENSINO DE CIÊNCIAS
}

\author{
CIENCIA FORENSE: UN ABORDAJE DE LA IDENTIFICACIÓN HUMANA EN LA \\ ENSEÑANZA DE CIENCIAS.
}

\section{FORENSIC SCIENCE: AN APPROACH TO HUMAN IDENTIFICATION IN SCIENCE TEACHING}

\author{
Apresentação: Comunicação Oral \\ Marcos Felipe Silva Lino'; Marcos Vinicios Ferreira de Sá ${ }^{2}$; Cleomacio Miguel da Silva ${ }^{3}$ \\ DOI: https://doi.org/10.31692/2358-9728.VICOINTERPDVL.2019.0077
}

\section{Resumo}

Este artigo tem como objetivo incentivar a promoção do ensino de ciências, usando, como modelo de aprendizagem, as interações com a ciência forense, visando estabelecer novas práticas pedagógicas de motivação para os alunos do ensino médio, através de experimentos básicos de coleta de impressões digitais. Com isto, busca-se a melhoria na qualidade de ensino, principalmente em relação às aulas práticas, proporcionando aos estudantes e professores de Educação Básica atividades extracurriculares e debates utilizando ciência forense e a investigação criminal. $\mathrm{O}$ ensino de ciências enfrenta muitos obstáculos. Geralmente, o conteúdo tem baixa aceitação entre os estudantes, com ênfase a conceitos abstratos que inibem a curiosidade e motivação dos alunos. Portanto, a presente pesquisa foi desenvolvida com a finalidade de elaborar experimentos de coleta, caracterização e identificação de impressões digitais, envolvendo a interdisciplinaridade e a contextualização de forma lúdica, abordando temas relacionados com a identificação humana. Essas atividades foram desenvolvidas para 37 alunos do $3^{\circ}$ ano do ensino médio de uma escola da rede privada do município de Paulista, no estado de Pernambuco. Foi realizada uma simulação de local de crime, composta por diversos indícios distribuídos pelo local, realizando a integração e dinâmica entre os estudantes. Isto possibilitou a participação efetiva dos alunos nas simulações das atividades propostas da rotina de trabalho de um perito criminal. Do total de 37 alunos entrevistados, $51 \%$ sabiam o conceito de identificação humana; $81 \%$ afirmaram que não conheciam os métodos utilizados no processo de identificacao humana; e 95\% dos alunos afirmaram não ter aulas práticas com frequência. Os dados obtidos na pesquisa indicam que os estudantes demonstraram interesse pela metodologia utilizada, visto que foi a primeira vez que todos participaram de uma relação entre teoria e prática ligada à ciência forense. Os dados

\footnotetext{
${ }^{1}$ Licenciatura em Ciências Biológicas, Universidade de Pernambuco, marcoshit9@hotmail.com

${ }^{2}$ Licenciatura em Ciências Biológicas, Universidade de Pernambuco, marcos.sa99@hotmail.com

${ }^{3}$ Doutor em Tecnologias Energéticas e Nucleares, Universidade de Pernambuco, cleomacio@hotmail.com
} 
apontam que as ciências da natureza ainda enfrentam uma baixa aceitação entre os estudantes, porém as aulas práticas colaboram para apreço, visto que ensinar ciência é um desafio. Nessa perspectiva, acredita-se que essa proposta de ensino contribui para um melhor entendimento sobre a contextualização. Afinal, pode-se afirmar que um ensino com aulas práticas torna-se uma importante ferramenta didática que aumenta o dinamismo, pois envolvem a contextualização, conhecimento prévio e o cotidiano dos aprendizes. Observam-se as potencialidades desta temática no âmbito escolar, principalmente para o ensino de ciências e suas tecnologias.

Palavras-Chave: Cena de crime, Ciências da natureza, Impressão digital, Investigação criminal.

\section{Resumen}

Este artigo tiene como objetivo incentivar la promoción del enseño de ciencias, como modelo del aprendizaje, las interacciones con la ciencia forense a fin de establecer nuevas prácticas pedagógicas de motivación para los alumnos del enseño medio, a través de experimentos básicos de la coleta de impresiones digitales. Con eso, se busca la mejora en la cualidad del enseño, principalmente en relación a las clases prácticas, proporcionando a los estudiantes y profesores de la Educación Básica actividades extracurriculares y debates utilizando la ciencia forense e la investigación criminal. La enseñanza de ciencias enfrenta muchas barrerlas. En general, el contenido tiene baja aceptación entre los estudiantes con énfasis a los conceptos abstractos que inhiben la curiosidad y motivación de los alumnos. Por tanto, la presente pesquisa fue desarrollada con la finalidad de elaborar experimentos de coleta, caracterización e identificación de las impresiones digitales, envuelta la interdisciplinaridad y la contextualización de forma lúdica, abordando temas con relación a la identificación humana. Estas actividades fueron desarrolladas para 37 alumnos del enseño medio de una escuela de la red privada en el municipio de Paulista, en el estado de Pernambuco. Se han cumplido una simulación de local del crimen, compostas por diversos indicios distribuidos por el local, también con la integración y dinámica entre los estudiantes, efectuándose la participación efectiva en las actividades propuestas de la rutina del trabajo de un perito criminal. Del total de 37 alumnos entrevistados, 51\% sabia el concepto de la identificación humana; $81 \%$ afirmaban que no han conocido sobre los métodos utilizados en la identificación humana; e 95\% de los alumnos afirmaban no tener clases prácticas frecuentemente. Los datos obtenidos en la pesquisa indican que los estudiantes han mostrado interés en la metodología utilizada, ya que fue la primera vez que todos han participado en una relación entre teoría y práctica vinculada a la ciencia forense. Los datos apontam que el ciencias de la naturaleza ainda enfrentam uma baja aceptación entre los estudiantes, sin embargo, las clases prácticas colaboran para apreciar, visto que enseñar ciencia es un desafío. En esa perspectiva, creerse que esa propuesta de la enseñanza aporta para lo mejor entendimiento sobre la contextualización. Al final, se puede afirmar que el enseño con clases prácticas, tornarse una importante herramienta didáctica que aumenta el dinamismo, pues es envuelto a la contextualización, conocimientos previos y el cotidiano de los aprendices. Observamos el potencialidades de esta temática en el ámbito escolar, principalmente para el enseño de ciencias y sus tecnologías. 
Palabras Clave: Escena criminal; ciencias de la naturaleza, impresión digital, investigación criminal.

\begin{abstract}
This article intend to promote the science teaching using the Forensic Science as model of learning, aiming to establish new pedagogical motivational practices for high school students through basic fingerprinting experiments. In this way, we seek to improve the quality of teaching, especially in relation to practical classes, providing students and teachers of basic education, extracurricular activities and debates using the Forensic Science and the Criminal Investigation. Furthermore, the education through practical science faces many obstacles. In general, the content has low acceptance among students, with, also, an emphasis on abstract concepts that limits student's curiosity and motivation. Therefore, this research was created in order to develop fingerprint collection, characterization and identification experiments, involving interdisciplinarity and contextualization in a playful way, addressing themes related to human identification. These activities were developed for 37 students in the third (last) year of High School at a private school in the city of Paulista, in Pernambuco. A crime scene simulation was performed, made up of several signs distributed throughout the place, stimulating the integration and dynamics among the students. This enabled the effective participation of students in simulations activities of a criminal expert routine. From the 37 students interviewed, $51 \%$ knew the concept of human identification; $81 \%$ said they did not know the methods used in the process of human identification; and $95 \%$ of students reported not having practical classes often. Thus, the data obtained in the research indicate that students showed interest in the methodology used, as it was the first time that all of them participated in a relation between theory and practice linked to the Forensic Science. That data indicates that the Natural Sciences still faces low acceptance among students, but, in the other hand, practical classes contribute to appreciation, because teaching science is a great challenge. From this perspective, it is believed that this teaching proposal contributes to a better understanding of the contextualization in education. Lastly, it can be stated that a learning with practical activities can be an important didactic to improve the dynamism, because it requires the contextualization, previous knowledge and a daily participations from the students. The potentialities of this theme in the school environment were observed, especially for science teaching and its technologies.
\end{abstract}

Keywords: Crime Scene, Natural Sciences, Fingerprint, Criminal Investigation.

\title{
Introdução
}

As ciências da natureza estão presentes no cotidiano e atividades diárias das pessoas. Existem as responsabilidades de profissionais e especialistas em formar e informar cidadãos acerca de fenômenos e situações corriqueiras. As ciências compõem a cultura científica e tecnológica que, como toda cultura humana, é resultado e instrumento da evolução social e econômica, na atualidade e ao longo da história. Sabe-se que, no ensino-aprendizagem, as 
atividades práticas proporcionam a curiosidade dos alunos e facilita a construção do conhecimento, promovendo satisfação e prazer (ALVES, 1994).

De acordo com os Parâmetros Curriculares Nacionais (PCN) de Ciências Naturais, o ensino de ciências permite introduzir e explorar as informações relacionadas aos fenômenos naturais como saúde, tecnologia, sociedade e meio ambiente, favorecendo a construção e ampliação de novos conhecimentos, um conjunto de atividades que oferecem uma visão científica do mundo real (ARCE et al. 2011). Segundo Soares et al. (2013), o professor pode propor projetos de investigação para dar maior sentido aos conteúdos abordados. O ensino de ciências deve fornecer subsídios para que o aluno seja capaz de se posicionar diante de questões da sociedade.

Dessa forma, os alunos de Ciências, por meio de atividades práticas, têm a possibilidade de investigação, comunicação, debate de fatos e ideias, possibilitando-os a observação e comparação, o que lhes favorece o modo de pensar em que há conexões entre ciências, tecnologia e sociedade (BARTZIK e ZANDER, 2016). No processo de escolarização, é importante que os alunos tenham oportunidades de participar de atividades investigativas, de realizar experimentos, testar hipóteses, questionar e apresentar suas opiniões, interagindo com os colegas (CAMARGO et al, 2015).

Nesse contexto, a Ciência da Identificação Humana pode ser trabalhada no ensino de ciências. Segundo Bittar (2019), a identidade humana é o conjunto de elementos característicos de uma pessoa, que a torna única, permitindo distingui-la das demais. Descreve-se identidade como a soma de caracteres que individualizam uma pessoa (SIEGEL, KNUPFER e SUUKKO, 2000 apud FREITAS, 2013). O processo técnico e cientifico empregado para determinar identidade é chamado de identificação (BITTAR, 2019). Nessa perspectiva, observa-se que, o conjunto de todos os conhecimentos científicos e técnicas utilizadas para auxiliar a justiça, são denominados de ciência forense, e esses conhecimentos são utilizados em assuntos legais, cíveis, penais ou administrativos (GARRIDO e GIOVANELLI, 2012). As impressões papilares fazem parte do grupo de identificação humana conclusiva (ESPINDULA, 2006). A análise de impressões digitais é objeto de estudo da datiloscopia, que trata da identificação humana por meio das papilas dérmicas (ARAÚJO e PASQUALI, 2006).

O ensino de ciências enfrenta muitos obstáculos, o conteúdo tem baixa aceitação entre os estudantes. Com conceitos abstratos, o gosto e curiosidade estão desaparecendo, 
promovendo um desempenho inesperado. $\mathrm{O}$ ensino é muito importante para o cotidiano e problemas ambientais. Este artigo tem como objetivo incentivar a promoção do ensino de ciências, usando como modelo a interdisciplinaridade entre os conhecimentos nas áreas de ciências da natureza e ciência forense. Busca-se, com isso, a elevação na qualidade de ensino através da aplicação de aulas práticas, baseadas no ensino por investigação, utilizando-se de conteúdos desencadeadores como a identificação de impressões digitais, proporcionando aos estudantes e professores de Educação Básica atividades extracurriculares e debates, utilizando ciência forense e a investigação criminal como elementos motivadores do processo ensinoaprendizagem.

\section{Fundamentação Teórica}

\section{A origem da ciência forense e sua aplicabilidade}

A ciência forense é a combinação de duas palavras latinas diferentes: forensis e scientia. A primeira, forense, refere-se a uma discussão ou exame realizado em público. Como os julgamentos no mundo antigo eram tipicamente realizados em público, ele carrega uma forte conotação judicial. A segunda é a ciência, que é derivada do grego para conhecimento, e está hoje intimamente ligada ao método científico. Em conjunto, a ciência forense pode ser entendida como o uso de métodos e processos científicos na solução de crimes (CRETELLA e CINTRA, 1956; SCHAFER, 2008; DOLAN, 2008)

A história do termo provém da época romana. O caso seria decidido em favor do indivíduo com o melhor argumento entregue ao público. Esta é a origem da palavra forense como uma forma de prova legal e como uma categoria de apresentação

pública (SCHAFER, 2008). É uma ciência interdisciplinar, empírica e sistemática, que se ocupa não apenas do crime, do criminoso, e da vítima, mas também do controle social das transgressões legais, gerando esquemas de interpretação e classificação de crimes e delitos (GOMES, 2007).

Os cientistas forenses podem estar envolvidos a qualquer momento numa análise científica objetiva. Para tanto, é necessário encontrar o veio da verdade intrínseca e buscar a justiça em um processo legal (AAFS, 2019). Um cientista forense irá analisar e interpretar as evidências, como também questionar os tribunais. Fica claro a partir dessa definição ampla, que a ciência forense é, portanto, a interseção entre a ciência e o sistema de justiça criminal, 
que requer uma abordagem multidisciplinar para entender completamente as possíveis utilizações e implicações da ciência aplicada ao contexto legal (CHEMELLO, 2006).

\section{Identificação humana por meio das impressões}

$\mathrm{Na}$ ciência forense, as pessoas podem ser identificadas por suas impressões digitais. Esta assertiva é apoiada pela filosofia de identificação de rebordo de fricção, que afirma que a identificação de rebordo de fricção é estabelecida através da concordância de formações de rebordo de fricção, em sequência, possuindo singularidade suficiente para individualizar (NIJ, 2016).

No século XVI, dentro do continente europeu, universitários e médicos começaram a reunir informações sobre causas de mortes ocorridas de modo ainda muito específico (KELLY, 2009). Porém, atualmente é considerada uma área interdisciplinar, pois envolve física, química, biologia, dentre outras. Num crime de homicídio, por exemplo, são utilizadas as informações dos fluídos corporais como sêmen, fio de cabelo, sangue e impressão digital (CHEMELLO, 2006). As impressões digitais latentes usadas em investigações criminais são, muitas vezes, peças cruciais de evidência que podem ligar um suspeito a um crime. Logo, são utilizadas técnicas da ciência forense para revelar ou extrair impressões digitais de superfícies e objetos, usando métodos químicos ou físicos. As imagens de impressões digitais podem ser fotografadas, marcadas para distinguir recursos por examinadores de impressões digitais latentes (NIJ, 2016). A técnica de pó é mais utilizada entre os peritos criminais, e nasceu juntamente com a observação das impressões e sua utilização remota no século XIX, dando continuidade até hoje. É usada quando as Impressões Papilares Latentes (IPL) localizam-se em superfícies que possibilitam o decalque da impressão, ou seja, superfícies lisas, não rugosas e não adsorventes (CHEMELLO, 2006).

\section{O ensino de ciências e propostas de ensino}

Nas diretrizes e parâmetros que organizam o ensino médio, as Ciências da Natureza tem a característica de investigação da natureza e dos desenvolvimentos tecnológicos, promovendo uma sistematização do conhecimento de fenômenos ou processos naturais e tecnológicos (BRASIL, 2002). O professor precisa criar alternativas e métodos de ensino que sejam eficazes, e que envolvam a atenção dos alunos, práticas que os instiguem e que os 
façam ter curiosidade e motivação para aprender. Essas atividades nas aulas de ciências são consideradas uma ferramenta fundamental para dar continuidade e favorecer a proposta dos PCN (BRASIL, 1997). Observa-se que, as atividades práticas têm potencial para abrir possibilidades de atingir novos conhecimentos, uma ideia de interação com os materiais de laboratórios, dentre outros. Por meio dessa interação, é criado um vínculo de aprendizagem que torna o indivíduo com mais suscetibilidade de descobertas e fixação dos conteúdos propostos de ciências (VASCONCELLOS, 1995).

Na prática escolar, não é de fácil acessibilidade interligar assuntos práticos da vida cotidiana, com assuntos teóricos ministrados em sala, além das dificuldades estruturais encontradas nas escolas, onde tais práticas se tornam ainda mais escassas. O objetivo do docente sempre será a contextualização dos problemas, e a interdisciplinaridade dos assuntos, porém, isso nem sempre é alcançado. Geralmente, os conteúdos de ensino de ciências são transmitidos de forma abstrata e fatigante. Entretanto, a ludicidade torna as aulas instigantes. A aula prática favorece a contextualização do conteúdo a ser ministrado em sala de aula e desperta grande interesse no discente (FILHO e ANTEDOMENICO, 2010). Os conhecimentos de criminalística aplicados à perícia criminal tornam-se, nesse contexto, uma importante ferramenta para estimular a interdisciplinaridade no ensino de Ciências Naturais (DUTRA e MONTEIRO, 2016).

\section{Metodologia}

O método utilizado para realização do levantamento de dados foi do tipo quantitativo. Segundo Richardson (1989), este método caracteriza-se pelo emprego da quantificação, tanto nas modalidades de coleta de informações, quanto no tratamento dessas através de técnicas estatísticas, desde as mais simples até as mais complexas. Essas técnicas são objetivadas pela pesquisa experimental que é um dos principais métodos da pesquisa quantitativa.

Sendo assim, esse método possui como diferencial a intenção de garantir a precisão dos trabalhos realizados, fazendo com que o resultado possua poucas chances de distorções. 


\section{Local do estudo}

O estudo foi desenvolvido numa Escola da Rede privada de Ensino localizada no município do Paulista-PE (Figura 1), a $17 \mathrm{~km}$ de distância do Recife, na Região Metropolitana.

Figura 1. Mapa do Estado de Pernambuco com destaque à cidade do Paulista

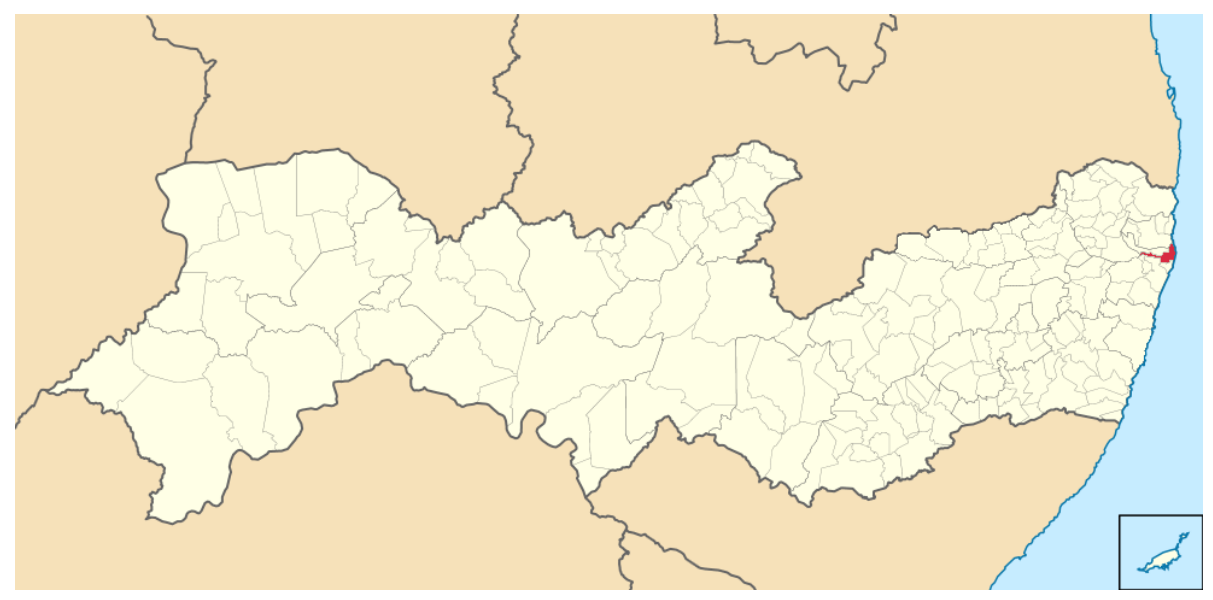

Fonte: Própria (2019)

\section{Materiais e métodos}

Como procedimento básico, optou-se pela realização de revisão bibliográfica, aplicação de questionários, aula expositiva e aula prática.

Foi definida, previamente, uma turma do $3^{\circ}$ ano do ensino médio, totalizando 37 alunos com idades entre 15 e 18 anos. Um questionário inicial foi aplicado para que fossem descobertos os conhecimentos prévios dos alunos sobre identificação humana, níveis de interesse em ciências da natureza e níveis de satisfação das aulas. A atividade foi apresentada em duas etapas:

\section{Primeira etapa}

A primeira consistiu de aulas expositivas, teóricas, com o propósito de informar os alunos acerca das técnicas utilizadas pela perícia criminal na identificação humana (Figura 2). Foram ministradas aulas de identificação humana com enfoque em datiloscopia. 
Figura 2. Ministração da aula de identificação da caracterização da digital e suas particularidades.

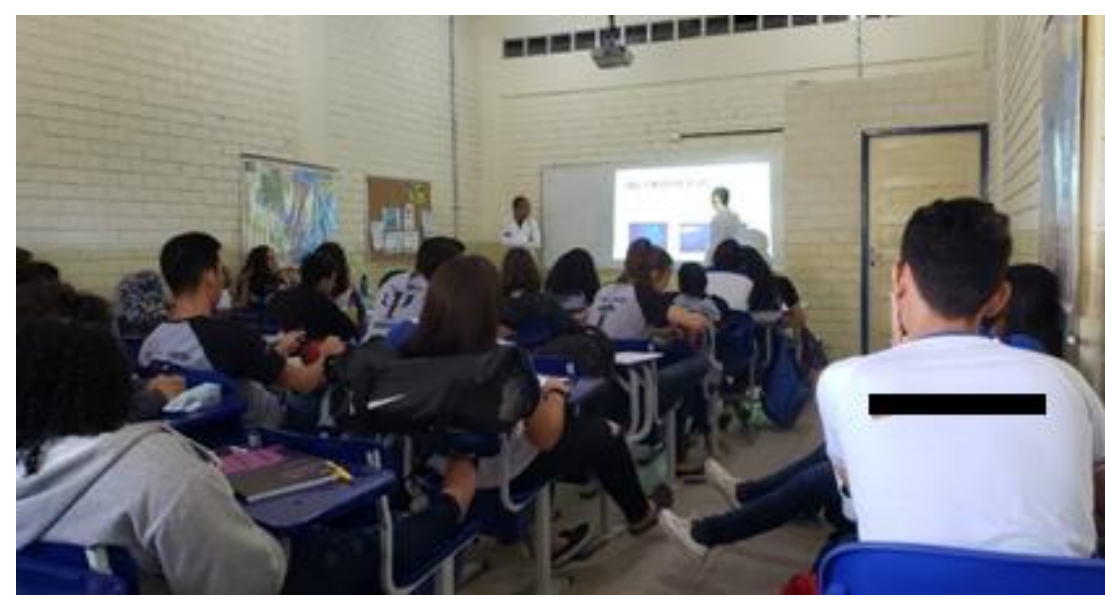

Fonte: Própria (2019)

\section{Segunda etapa}

Consistiu em aula prática, onde os alunos foram divididos em sete grupos. Esta etapa permitiu o contato com simulação de local de crime, composta por diversos indícios distribuídos pelo local. Criaram-se, então, relações dinâmicas entre os estudantes, possibilitando a participação efetiva nas atividades propostas da rotina de trabalho de um perito criminal.

O estudo incidiu em elaborar um experimento de coleta, caracterização e identificação de impressões digitais, envolvendo a interdisciplinaridade e a contextualização de forma lúdica para abordar o tema de identificação humana.

A técnica de pó foi utilizada para coleta de impressões digitais. A atividade, em sua totalidade, necessitou de três aulas para a aplicação do conteúdo programado.

Materiais utilizados: Pó revelador, laudo técnico, almofariz, pistilo, luvas, lanterna, papel Celofane, pinceis e fita adesiva.

Procedimentos: foi criado dentre a mistura de óxido de ferro, carvão mineral e carbono amorfo o (Pó revelador), sendo triturados no almofariz e pistilo, até obter um pó bem fino (Figura 3). 
Figura 3. Pó revelador para impressões latentes

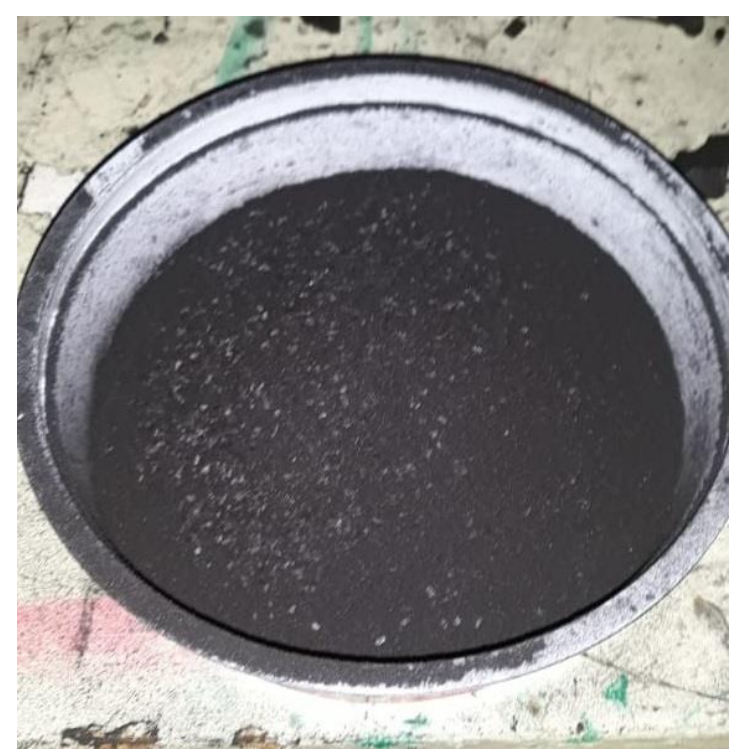

Fonte: Própria (2019)

$\mathrm{Na}$ Cena de crime, foi colocada a impressão digital a ser revelada em copos de vidro e celulares (Figura 4), simulando objetos de uma cena de crime. Buscou-se a revelação das impressões digitais através de uma lanterna (Figura 5), e foi modificada a cor desta lanterna para contraste de cores através do uso de papel Celofane (cor vermelha) que é um polímero natural derivado da celulose, que foi utilizado como filtro (Figura 6) simulando uma luz forense utilizada pelos peritos criminais nas cenas de crimes reais.

Figura 4. Impressão digital na superficie de um aparelho celular

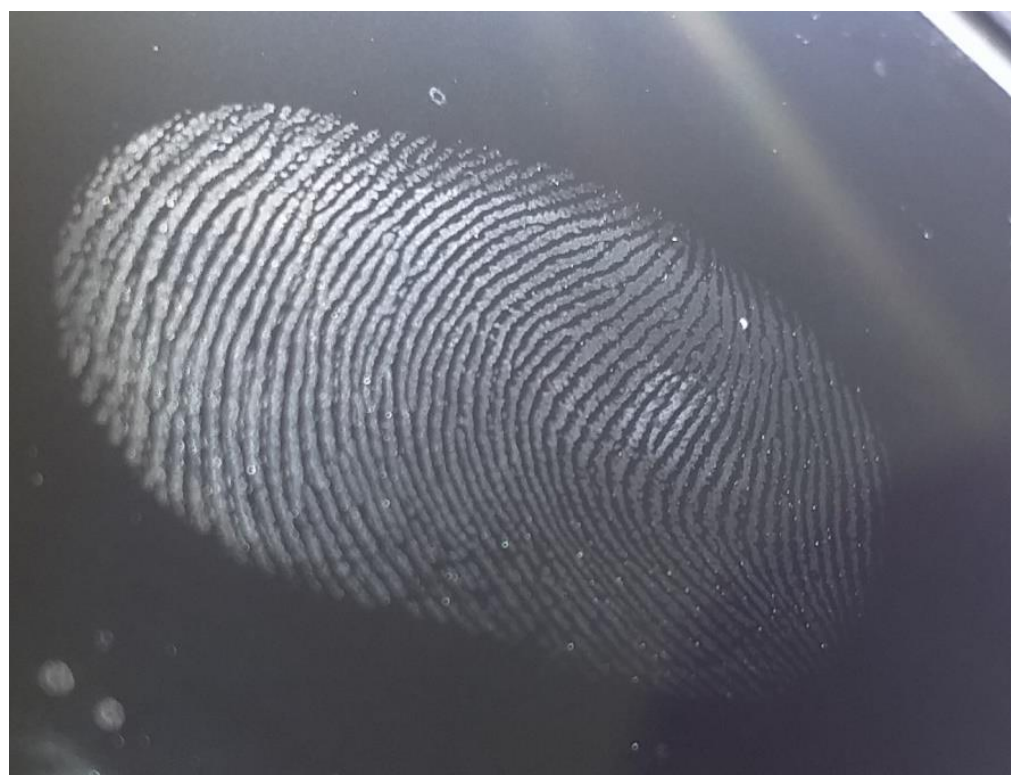

Fonte: Própria (2019) 
Figura 5. Impressão digital revelada com lanterna

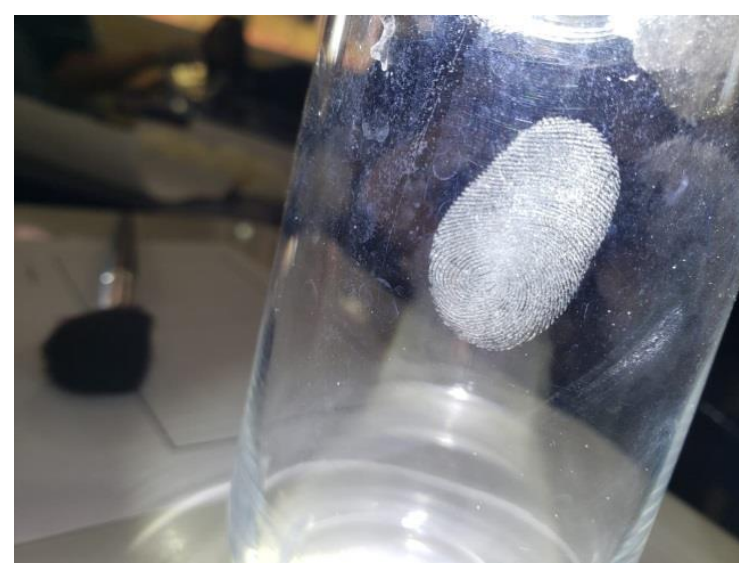

Fonte: Própria (2019)
Figura 6. Simulação de luz forense

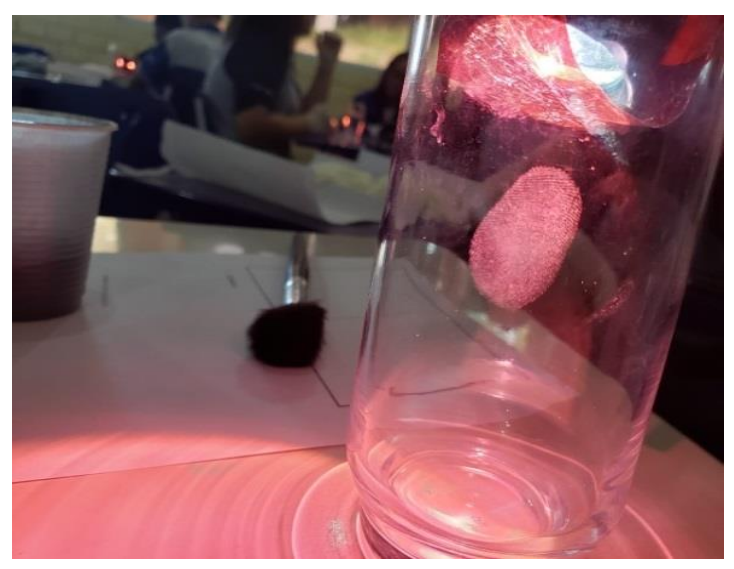

Fonte: Própria (2019)

Após simular através da lanterna, com ajuda de um pincel, foi aplicado o pó revelador (Figura 7) sobre a superfície do copo. Este pó foi posto sobre a digital, e em seguida foi retirado o excesso com um pincel.

Figura 7. Impressão digital revelada pela técnica do pó

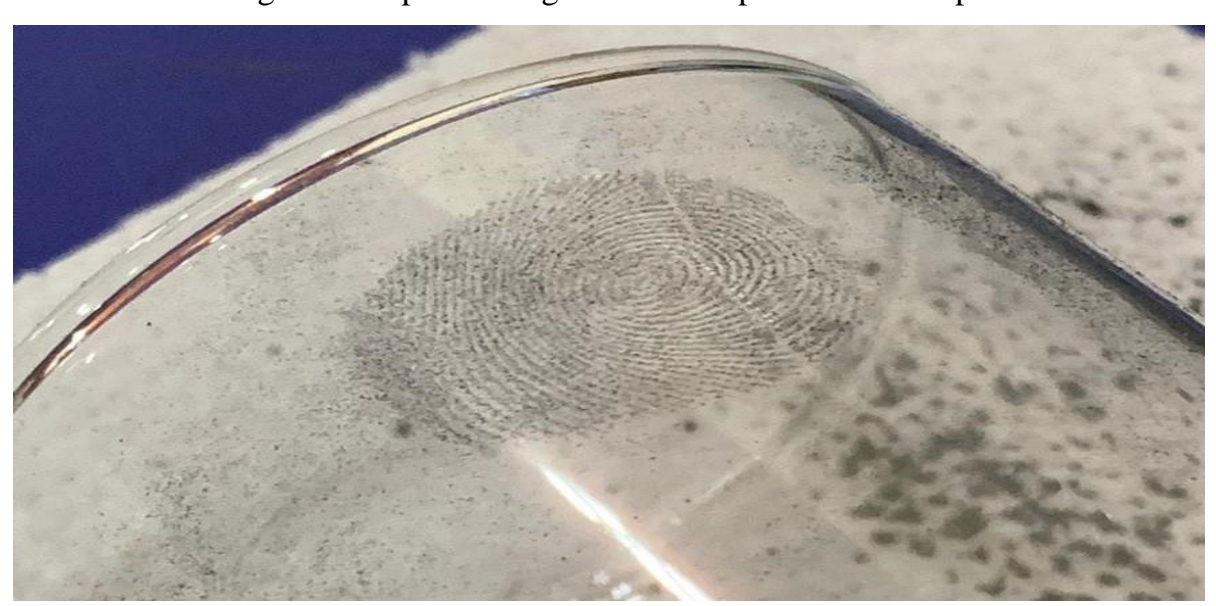

Fonte: Própria (2019)

A fita adesiva foi utilizada para coletar as impressões digitais (Figura 8 e 9). O conceito de sobreposição foi aplicado para comparação de impressões digitais. 
Figura 8. Impressão digital coletada

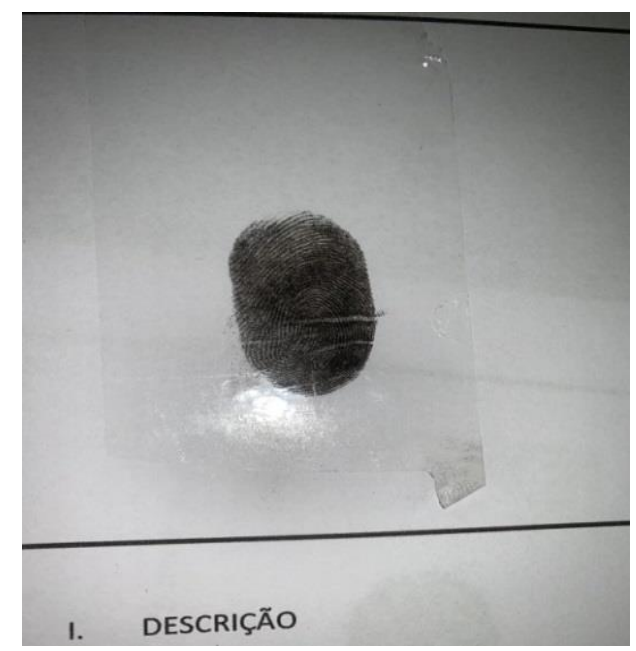

Fonte: Própria (2019)
Figura 9. Impressão digital ampliada

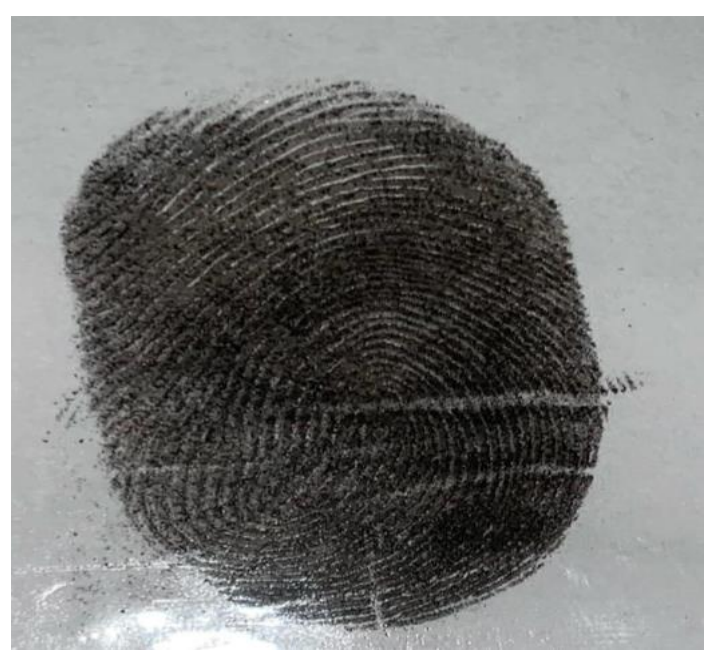

Fonte: Própria (2019)

O laudo pericial criminal (Figura 10) envolve conhecimentos técnicos e científicos, instrumento que descreve, quantifica, caracteriza e valoriza o crime na persecução penal do local. Este foi preenchido no fim da atividade para documentação dos resultados das análises obtidas pelos alunos.

Figura 9. Laudo com descrições e características das coletas

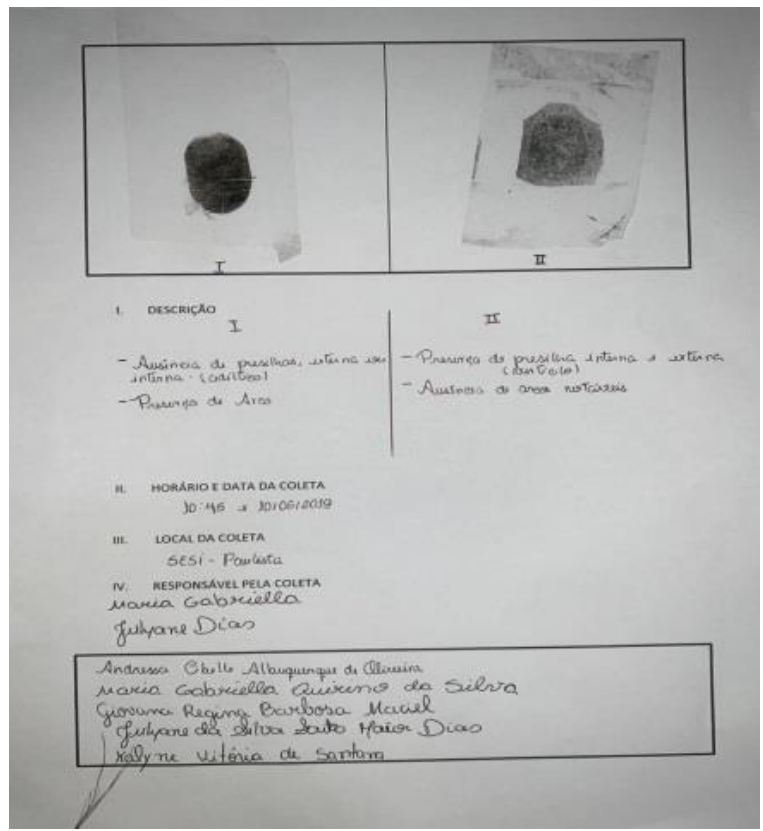

Fonte: Própria (2019) 
Por fim, um novo questionário foi aplicado com a finalidade de analisar a metodologia forense de identificação humana, além de servir para alcançar os objetivos propostos na aula prática. Por conseguinte, em consonância com a continuação da proposta, salienta-se que, foram entregues cartas de apresentação, termos de consentimento livre esclarecido para gestão escolar, assim como para estudantes menores de idade, com assinaturas de responsáveis para participação nas aulas práticas de pesquisa.

\section{Resultados e Discussão}

No questionário inicial, dos 37 alunos entrevistados, 51\% afirmaram saber o conceito de identificação quando lhes foram perguntados sobre os métodos utilizados no processo de identificacao humana; $81 \%$ dos alunos afirmaram não ter conhecimento dos métodos utilizados; e 95\% dos alunos afirmaram não ter aulas práticas com frequência. Foram perguntados acerca do nível de interesse em ciências da natureza (Figura 11).

Figura 10. Níveis de interesse dos alunos em relação às ciências da natureza

\section{Níveis de interesse por disciplina}

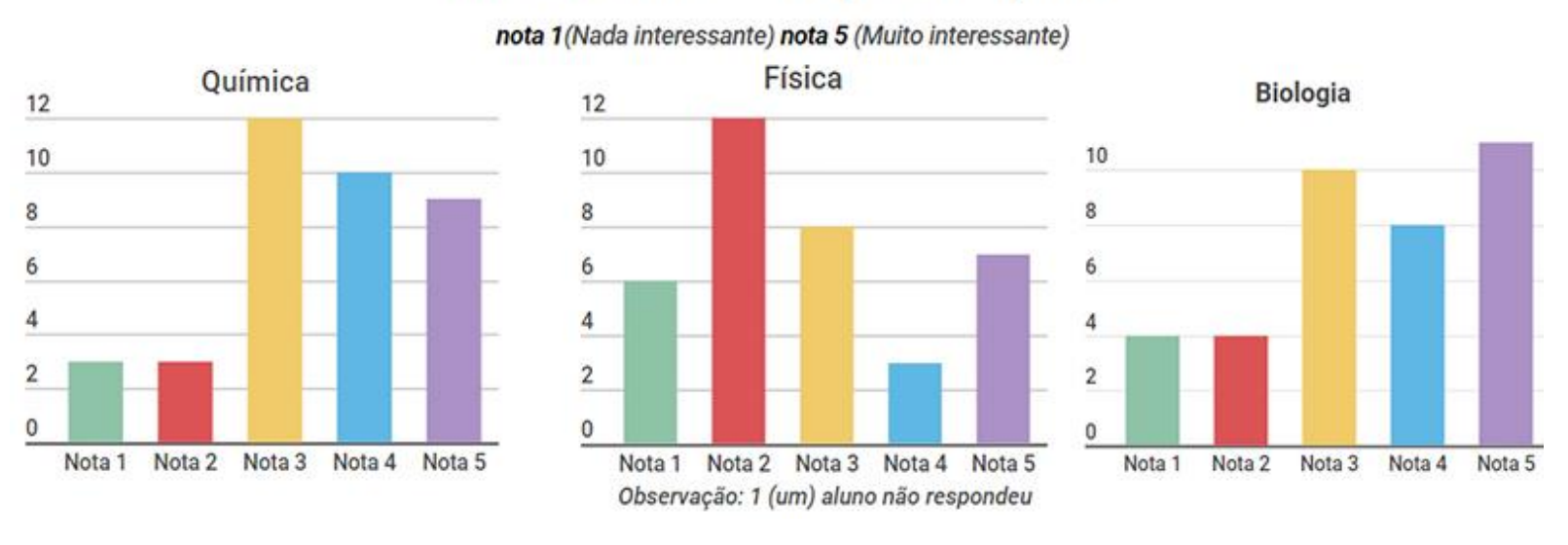

Fonte: Própria (2019)

Partindo desse pressuposto, o fato obtido através da análise desta questão revela que os estudantes têm uma significativa média de interesse em Química e Biologia. Sabe-se que, a relação dos alunos com a Química e as outras Ciências da Natureza, sempre foi um grande problema na sala de aula das escolas brasileiras (SCHNETZLER e ARAGÃO, 1995).

Para verificar o nível de satisfação dos alunos com as aulas de Ciências Naturais, foram considerados nesse estudo, nota 1 (totalmente insastifeito) e nota 5 (totalmente satisfeito). Os resultados obtidos encontram-se apresentados na Tabela 1. 
Tabela 1. Níveis de satisfação de como as aulas são lecionadas.

\begin{tabular}{|c|c|c|c|}
\hline $\begin{array}{c}\text { NOTA DE } \\
\text { SATISFAÇÃO }\end{array}$ & QUÍMICA & FÍSICA & BIOLOGIA \\
\hline $\mathbf{1}$ & 0 alunos $-0 \%$ & 3 alunos $-8 \%$ & 17 alunos $-46 \%$ \\
\hline $\mathbf{2}$ & 2 alunos $-5 \%$ & 16 alunos $-43 \%$ & 10 alunos $-27 \%$ \\
\hline $\mathbf{3}$ & 7 alunos $-19 \%$ & 7 alunos $-19 \%$ & 9 alunos $-24 \%$ \\
\hline $\mathbf{4}$ & 17 alunos $-46 \%$ & 7 alunos $-19 \%$ & 1 alunos $-3 \%$ \\
\hline $\mathbf{5}$ & 11 alunos $-30 \%$ & 4 alunos $-11 \%$ & 0 alunos $-0 \%$ \\
\hline TOTAL & $\mathbf{3 7}$ alunos $-\mathbf{1 0 0 \%}$ & $\mathbf{3 7}$ alunos $-\mathbf{1 0 0 \%}$ & $\mathbf{3 7}$ alunos $-\mathbf{1 0 0 \%}$ \\
\hline
\end{tabular}

Fonte: Própria (2019)

Evidencia-se, com os dados apontados na figura 11, que, apesar dos níveis de insatisfação demonstrados acerca do levantamento em relação ao grau de satisfação dos alunos, é notória a grande disparidade entre Química e Biologia. Por mais que haja maior interesse por parte dos alunos com relação à disciplina de Biologia, os dados obtidos levam a acreditar que estejam enfrentando uma maior dificuldade quando se fala desta disciplina, pois $46 \%$ dos alunos afirmaram estar totalmente insatisfeitos com a forma que as aulas são ministradas. Neste caso, um dos possíveis fatores para insatisfação das aulas são os conteúdos não contextualizados adequadamente, ficando distantes da realidade dos estudantes, diminuindo o nível de interesse pelas aulas e pela disciplina (SCHNETZLER e ARAGÃO, 1995).

No questionário final, $100 \%$ dos alunos afirmaram que nunca tinham participado de alguma prática utilizando a metodologia forense. A importância da prática e da metodologia aplicada foi sondada (Figura 12 e 13). 
Figura 11. Gráfico de barras mostrando os quantitativos das respostas.

\section{A importância da prática para o entendimento dos conteúdos}

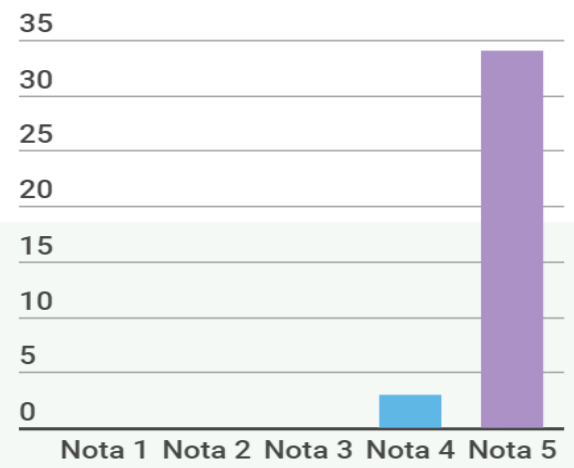

Nota 1 (pouco importante) Nota 5 (muito importante)

Fonte: Própria (2019)
Figura 13. Respostas dos estudantes ao tema transversal aplicado.

\section{0 que achou da Metodologia Forense no ensino de Ciências?}

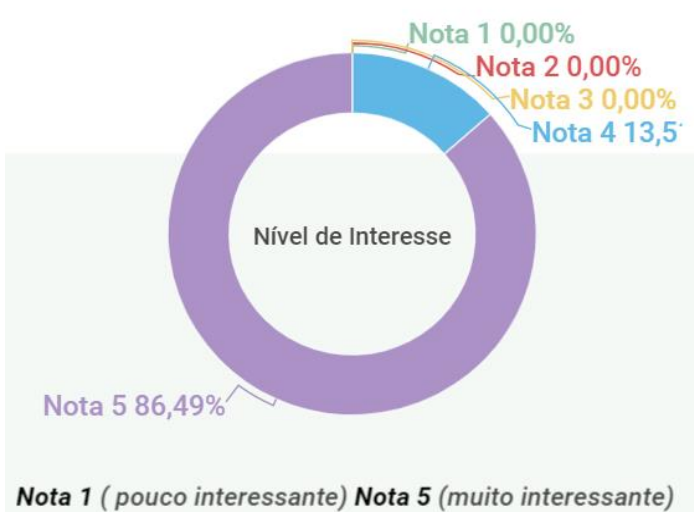

Fonte: Própria (2019)

Dando ênfase as respostas que ilustram a importância das aulas práticas e da metodologia utilizada no ensino de ciências, demonstra-se que as aulas práticas são consideradas de suma importância para os estudantes, aumentando o nível de interesse em temas desencadeadores como a criminalística e a ciência forense.

As simulações de práticas forenses de impressões digitais contribuíram no despertar científico dos alunos, estabelecendo interligação entre teoria e prática, promovendo a curiosidade e ajudando-os a mantê-los motivados dentro do processo ensino-aprendizagem. Tudo isso pode ser comtemplado nas atividades práticas para o melhor aprendizado dos conteúdos teóricos trabalhados em sala de aula (ZANON e PALHARINI, 1995). O método de ensino predominante utilizado é o tradicional, onde se busca somente a fixação de conhecimentos, conteúdos e informações, não se atentando para os processos de aprendizagem através da motivação (MIZUKAMI, 1986). Na Tabela 2 foi permitida a opção de marcar mais de uma alternativa sobre as necessidades de metodologias nas aulas. 
Tabela 2. As metodologias que faltam nas aulas dos estudantes

\begin{tabular}{|c|c|c|c|}
\hline METODOLOGIAS & QUÍMICA & FÍSICA & BIOLOGIA \\
\hline AULAS & 34 & 26 & 36 \\
\hline PRÁTICAS/LABORATÓRIO & & & 30 \\
\hline RULAS DE CAMPO & 28 & 27 & 14 \\
\hline OUTROS & 6 & 8 & 19 \\
\hline NADA & 4 & 4 & 0 \\
\hline
\end{tabular}

Fonte: Própria (2019)

Dentre as metodologias de ensino utilizadas pelos professores e que satisfazem mais aos alunos, destacam-se as aulas de laboratório e de campo, porém os dados indicam uma lacuna em relação a essas metodologias nas aulas, podendo ser fatores que contribuem para os níveis de interesse pelas disciplinas (Figura 11) e satisfações de como as aulas são ministradas (Tabela 1). Em relação aos recursos utilizados pelos professores em sala de aula, os dados fazem referência de que há uma boa interação com os recursos digitais.

Quando o ensino acontece de uma única forma, não se obtêm os resultados almejados. Deve-se, portanto, neutralizar a situação de passividade, mas a forma pelas quais as metodologias, geralmente tradicionais, são aplicadas, não favorecem a participação ativa e o envolvimento efetivo dos alunos (ROSA et al, 2013).

A aula teórica expositiva dos conteúdos de biologia se mantém como a opção didática mais usada pelos professores, devido a sua praticidade na ministração (SILVA et al, 2011). A importância do trabalho prático é inquestionável na disciplina de ciências e biologia, e deveria ocupar lugar central no seu ensino (SMITH, 1998). Quando perguntados como consideravam a estrutura da sua escola para realização de aulas práticas, foram obtidos os resultados apresentados na Tabela 3. 
Tabela 3. Estrutura da escola para desenvolver aulas práticas

\begin{tabular}{|l|c|c|c|c|c|c|}
\hline Pouco & Nota 1 & Nota 2 & Nota 3 & Nota 4 & Nota 5 & Muito \\
adequada & $\mathbf{4}$ & $\mathbf{1}$ & $\mathbf{1 0}$ & $\mathbf{1 7}$ & $\mathbf{6}$ & adequada \\
& alunos & aluno & alunos & alunos & alunos & \\
\hline
\end{tabular}

Fonte: Própria (2019)

No que diz respeito à estrutura da escola, mostra-se adequada para o desenvolvimento de aulas práticas, apresentando itens de infraestrutura física e organizacional, com laboratório de ciências a disposição e dependências adequadas para realização de aulas práticas. Ao utilizar, na sala, novas metodologias como as aulas práticas no ensino de ciências, percebe-se uma relação entre o aprendiz e os objetos de seu conhecimento, a teoria e a prática (LIMA et al, 1999). O desenvolvimento de recursos didáticos que se aproximem a realidade dos alunos se faz necessário para estreitar a teoria da prática, isto é, montar um laboratório na sala de aula, mesmo que seja com materiais de baixo custo, de modo que supra às necessidades dos alunos e do professor durante as aulas práticas (AFONSO e LEITE 2001).

\section{Conclusões}

Este trabalho apresentou uma proposta de viabilidade ao trabalhar com a ciência forense, ressaltando a importância de relacionar os conteúdos abordados no ensino médio com práticas de identificação humana.

Os dados obtidos na pesquisa indicam que os estudantes demonstraram interesse pela metodologia utilizada, visto que foi a primeira vez que todos participaram de uma relação entre teoria e prática ligadas a ciência forense. Os dados apontam que as ciências da natureza ainda enfrentam uma baixa aceitação entre os estudantes, porém que as aulas práticas colaboram para apreço, visto que ensinar ciência é um desafio. Nessa perspectiva, acredita-se que essa proposta de ensino contribui para um melhor entendimento sobre a contextualização.

Afinal, pode-se afirmar que um ensino com aulas práticas, torna-se uma importante ferramenta didática que aumenta o dinamismo, pois envolvem a contextualização, conhecimento prévio e o cotidiano dos aprendizes. Observaram-se as potencialidades desta temática no âmbito escolar, principalmente para o ensino de ciências e suas tecnologias. 


\section{Referências}

American Academy of Forensic Science (AAFS). Whats is forensic Science? Disponível em: https://www.aafs.org/home-page/students/choosing-a-career/what-is-forensic-science/. Acesso em 11 jul. de 2019.

ALVES, R. A alegria de ensinar. $3^{\text {a }}$ edição. ARS Poética Editora ltda, 1994.

ARAÚJO, M. E. C.; PASQUALI, L. Datiloscopia - A Determinação dos Dedos, Editora: Labpam., 2006.

ARCE, A; SILVA, D. A. S. M.; VAROTTO, M. Ensinando ciências na educação infantil. Campinas: Alínea, 2011.

BARTZIK, F.; ZANDER, L. D. A importância das aulas práticas de ciências no ensino fundamental. Revista @ rquivo Brasileiro de Educação, Belo Horizonte, v.4, n. 8, 2016.

BITTAR, Neusa. Medicina Legal e Noções de Criminalística, $8^{\text {a }}$ Ed, Editora Millennium, 2019.

BRASIL. Ministério da Educação. Secretaria de Educação Fundamental. Parâmetros Curriculares Nacionais: ciências naturais. Brasília, 1997.

CAMARGO, N. S. J.; BLASZKO, C. E.; UJIIE, N. T. O ensino de ciências e o papel do professor: concepções de professores dos anos iniciais do ensino fundamental. Xll Congresso Nacional de Educação, 2015.

CHEMELLO, Emiliano. A Ciência Forense: Impressões digitais. Química Virtual, 2006.

CRETElLA, Jr. ; CINTRA, G. de U. Dicionário latino-português. 7.ed. São Paulo: Companhia Editora Nacional, 1956.

CLAUDEMIR RODRIGUES DIAS FILHO; EDILSON ANTEDOMENICO. A Perícia Criminal e a Interdisciplinaridade no Ensino de Ciências Naturais. Disponível em: <http://qnesc.sbq.org.br/online/qnesc32_2/02-QS-6309.pdf>. Acesso em: 11 jun. 2019.

DOLAN, J. A. . Forensic analysis of fire debris,Handbook of Analytical Separations,Elsevier $\quad$ Science, 2008.2 Disponível em: <http://www.sciencedirect.com/science/article/pii/S1567719206060268>. Acesso em 10 ago. de 2019.

DUTRA, R.; MONTEIRO, S. A Perícia Forense Como Ferramenta No Ensino De Física. v. 01, p. 168-172, 2016. 
ESPÍNDULA, A. Perícia Criminal e Cível. Uma visão completa para peritos e usuários da perícia. $2^{\mathrm{a}}$.ed, Millennium, 2006.

FREITAS, Rodolfo Barbosa de. Sistemas de identificação humana no âmbito criminal. Campina Grande- 2013.2 Disponível em: <http://dspace.bc.uepb.edu.br/jspui/bitstream/123456789/11024/1/PDF\%20\%20Rodolfo\%20 Barbosa\%20de\%20Freitas.pdf $>$. Acesso em: 1 jun. de 2019.

GARRIDO, R. G. ; GIOVANELLI, A. . Criminalística: origens, evolução e descaminhos. Cadernos de Ciências Sociais Aplicadas, 2012.

GOMES M. B. . Who is guilty? what television police shows teach us. Journal of Experimental Psychology: General, v. 136, n. 1, p. 23-42, 2007.

KELLY, Jack. Gunpowder: Alchemy, Bombards, and Pyrotechnics: The History of the Explosive That Changed the World. Basic Books, 2009.

LEITE, L.; AFONSO, A. Aprendizagem baseada na Resolução de Problemas. Boletín das Ciências, Santiago de Compostela, n. 48, p. 253-260, 2001.

LIMA, M. E. E. C.; AGUIAR JÚNIOR, O. G.; BRAGA, S. A. M. Aprender Ciências - um mundo de materiais. Belo Horizonte: UFMG. 1999.

MEC; BRASIL. Parâmetros Curriculares Nacionais. Disponível em: <http://portal.mec.gov.br/seb/arquivos/pdf/ciencian.pdf>. Acesso em: 10 jul. 2019.

MIZUKAMI, M.G. Ensino: as abordagens do processo. São Paulo: Pedagógica e Universitária, 1986.

National Institute of Justice (NIJ). Fingerprints: An Overview nation, 2016. Disponível em: <https://www.nij.gov/topics/forensics/evidence/impression/pages/fingerprints.aspx\#note1>. Acesso em 17 jul. de 2019.

RICHARDSON, Roberto Jarry. Pesquisa social: métodos e técnicas. São Paulo: Atlas, 1989.

ROSA, Mauricio Ferreira da; SILVA, Priscila Sabino da; GALVAN, Francielli De Bona. Ciência Forense no Ensino de Química por Meio da Experimentação. Disponível em: <http://qnesc.sbq.org.br/online/prelo/RSA-40-13.pdf>. Acesso em 25 jun. de 2019.

SCHNETZLER, R. P.; ARAGÃO, R. M. R.; Importância, sentido e contribuições de pesquisas para o ensino de química. Química Nova na Escola, São Paulo, n.1, p.27- 31, 1995.

SIEGEL, J. KNUPFER, G E SUUKKO, Encyclopedia of Forensic Sciences 2nd Edition, 2250p. , 2013.

SILVA, F.S.S. da.; MORAIS, L.J.O.; CUNHA, I.P.R. . Dificuldades dos professores de 
Biologia em ministrar aulas práticas em escolas públicas e privadas do município de Imperatriz (MA). Revista UNI, Imperatriz, 2011.

SMITH, K.A. Experimentação nas Aulas de Ciências. In: CARVALHO, A.M.P.; VANNUCCHI, A.I.; BARROS, M.A.; GONÇALVES, M.E.R.; REY, R.C. Ciências no ensino fundamental: O conhecimento físico. 1. ed. São Paulo: Editora Scipione, 1998.

SCHAFER, E. Ancient science and Forensis. In: Embar-Seddon A, Pass AD, eds. Forensic Science. Salem Press; 2008; 40-43.

SOARES, A. C.; MAUER, M. B.; KORTMANN, G. L. Ensino de ciências nos anos iniciais do ensino fundamental: possibilidades e desafios em Canoas-RS. Revista Educação, Ciência e Cultura. Canoas, v. 18, n. 1, 2013.

VASCONCELLOS, C. D. S. Planejamento: plano de ensino: aprendizagem e projeto educativo. 4.ed. São Paulo: Libertad, 1995.

ZANON, L.B; PALHARINI, E.M.; A química no ensino fundamental de ciências. Disponível em: <http://qnesc.sbq.org.br/online/qnesc02/relatos.pdf>. Acesso em 10 jul. de 2019. 